The Official Journal of the Kettil Bruun Society for Social and Epidemiological Research on Alcohol

\title{
An update on alcohol use and risk of HIV infection in sub-Saharan Africa: Meta-analysis and future research directions
}

\author{
Sarah E. Woolf-King ${ }^{1,2}$, Craig M. Steinmaus², Arthur L. Reingold ${ }^{2}$, and Judith A. Hahn ${ }^{3}$ \\ ${ }^{1}$ Department of Medicine, Center for AIDS Prevention Studies, University of California, San Francisco, CA, United States \\ ${ }^{2}$ School of Public Health, University of California, Berkeley, CA, United States \\ ${ }^{3}$ Department of Medicine, Division of Infectious Diseases, University of California, San Francisco, CA, United States
}

\begin{abstract}
Aims: Sub-Saharan Africa is disproportionately affected by HIV/AIDS, and growing evidence suggests that alcohol consumption is a co-occurring problem in the region. We conducted a meta-analysis on studies of alcohol use and HIV infection in subSaharan Africa in order to assess associations, evaluate heterogeneity in the literature, identify susceptible subgroups, and suggest avenues for future research.
\end{abstract}

Design: We performed a systematic review, including published review articles and electronic database searches, and identified 35 studies on alcohol use and HIV.

Setting and participants: All of the studies included in the meta-analysis occurred with adults in sub-Saharan Africa.

Measurements: Pooled odds ratio $(O R)$ estimates were calculated using both the fixed inverse variance weighting method and the random effects method when evidence of heterogeneity was present.

Findings: The pooled $O R$ estimate for all studies was 1.61 (95\% CI: 1.44-1.80). The association between alcohol use and prevalence or incident HIV infection was particularly large among samples who reported problem drinking $(O R=2.17,95 \%$ CI: 1.64-2.87) and drinking in sexual contexts $(O R=1.79,95 \%$ CI: 1.55-2.06). Some evidence of publication bias was present; however, the $O R$ remained statistically significant in small and large studies and with population-based and high-risk samples.

Conclusions: These results suggest that alcohol consumption, particularly at high levels and in sexual contexts, is associated with an increased risk of HIV infection. An increased focus on methods that allow for more sensitive tests of the event-level association between alcohol consumption and risk of HIV infection may provide a better understanding of the causal mechanisms underlying this relationship.

The HIV epidemic in sub-Saharan Africa (SSA) is wellknown for being the most severe in the world. As seen in Table 1, although SSA accounts for only $10 \%$ of the world's population, approximately $65 \%$ of all adults living with HIV are found in this region (UNAIDS, 2006). Consequently, research investigating correlates of HIV acquisition as a means of informing prevention efforts remains a high public health priority. The World Health Organization's (WHO) 2011 Global Status Report on Alcohol and Health revealed that, although approximately $70 \%$ of Africans are self-reported "abstainers," levels of alcohol consumption among "drinkers" are alarmingly high. Table 2 presents the WHO's estimates for per capita alcohol consumption across SSA and reveals that several countries (e.g., Mali, South Africa, Uganda) have among the highest levels of per capita alcohol consumption in the world. For example, although $73 \%$ of South Africans report no alcohol consumption in the last year, the $25 \%$ who do drink report consuming 35 liters of pure alcohol in a one-year period. This translates into approximately 700 liters of $5 \%$ alcohol by volume beer per year. Furthermore, the heavy, episodic pattern of alcohol consumption among those who drink in SSA is one that is particularly likely to result in negative consequences, such as unprotected sex and HIV infection.

A growing body of research in SSA has revealed consistent evidence of a strong correlation between alcohol use and high-risk sexual behavior (e.g., sex without a condom) as well as alcohol use and HIV/STI infection (Fisher, Bang, \& Kapiga, 2007; Kalichman, Simbayi, Kaufman, Cain, \& Jooste, 2007; Pithy \& Parry, 2009; Woolf-King \& Maisto, 2011). It is hypothesized that individuals who consume alcohol immediately prior to a sexual event are

Correspondence: Sarah E. Woolf-King, Ph.D., M.P.H., University of California, San Francisco, Center for AIDS Prevention Studies, 50 Beale St., Suite 1300, San Francisco, CA, 94105, United States. E-mail: sarah.woolf-king@ucsf.edu

Financial support: This work was support by a T32 grant from the National Institute of Mental Health (NIMH T3219105 22).

Keywords: alcohol, HIV, Africa 
subsequently more likely to engage in high-risk sexual behavior that results in HIV infection (Dingle \& Oei, 1997; Goldman, Del Boca, \& Darkes, 1999; Steele \& Josephs, 1990). Three methodological approaches have been used to investigate the relationship between alcohol consumption and HIV infection (Cooper, 2002). Global association studies address the hypothesis that an individual who consumes alcohol is generally more likely to engage in high-risk sexual behavior, and consequently more likely to be HIV-positive. These studies correlate some measure of alcohol use with a measure of high-risk sexual behavior or with HIV infection status. In contrast, situational overlap studies ask participants if they "use alcohol in sexual contexts" and then correlate this binary exposure with HIV infection status and/or a measure of sexual risk behavior. Finally, event-level studies assess the amount of alcohol consumed during a specific sexual event, and what type of sexual risk behavior characterized that event (Weinhardt \& Carey, 2000). There is a notable lack of event-level research in SSA, even though this has been advocated as the best way to address the causal and temporal association between alcohol consumption and high-risk sexual behavior that results in HIV infection (Hendershot \& George, 2007; Woolf-King \& Maisto, 2011).

Fisher, Bang, and Kapiga (2007) conducted a systematic review and meta-analysis of 20 studies that investigated the association between alcohol consumption and HIV status, and found that alcohol users (collapsed across all levels of use) had significantly higher odds of being HIV-positive compared to non-drinkers. However, at the time of this review, situational association studies were uncommon, and consequently subgroup analyses could not be performed. Furthermore, since publication of Fisher and colleagues' (2007) review, at least 15 new studies have been published on the topic, several of which investigated the situational association between alcohol use and HIV infection.
Consequently, we conducted an updated systematic review and meta-analysis on the association between alcohol use and HIV status in SSA to (1) update this rapidly growing literature, (2) conduct subgroup analyses on the situational association between alcohol use and HIV risk, and (3) evaluate the necessity of continued research on this topic.

\section{Method}

\section{Literature review}

Studies published before 2009 were collected from our previous narrative review of the literature (Woolf-King \& Maisto, 2011), and were supplemented by a more recent search of electronic databases to update the review through 2010. Of the 20 studies included in Fisher and colleagues' meta-analysis, 19 were retained for inclusion in the present study (Ao, Sam, Masenga, Seage, \& Kapiga, 2006; Ayisi et al., 2000; Braddick et al., 1990; Demissie, Amre, \& Tsega, 1996; Fritz et al., 2002; Hargreaves et al., 2002; Kapiga, Lyamuya, Lwihula, \& Hunter, 1998; Kapiga et al., 2002; Kapiga et al., 2006; Lewis et al., 2005; Mbulaiteye et al., 2000; Mnyika, Klepp, Kvåle, \& Ole-King’ori, 1996; Ndina-Achola et al., 1997; Sebit et al., 2003; Simbayi et al., 2004; Talbot et al., 2002; Tengia-Kessey, Msamanga, \& Moshino, 1998; Zablotska et al., 2006; Zuma, Gouws, Williams, \& Lurie, 2003) and one (Gilgen, Williams, \& Campbell, 2000) was excluded for failing to meet the inclusion criteria specified below (i.e., it was not published in a peer-reviewed journal). An additional eight nonoverlapping studies published prior to 2009 were identified from our previous narrative review (Allen et al., 1992; Bassett et al., 1996; Clift et al., 2003; Dunkle et al., 2004; Fisher, Cook, Sam, \& Kapiga, 2008; Msuya et al., 2006; St. Lawrence et al., 2006; Zablotska et al., 2009) and three additional studies reported in Pithy and Parry (2009)

Table 1

UNAIDS Global and regional estimates for number of adults living with HIV, 2009

\begin{tabular}{lccc}
\hline Region & $\begin{array}{c}\text { HIV prevalence (\%) among } \\
\text { adults (15-49) }\end{array}$ & $\begin{array}{c}\text { Number of adults (15+) } \\
\text { living with HIV }\end{array}$ & $\begin{array}{c}\text { \% of all adults living } \\
\text { with HIV }\end{array}$ \\
\hline Global & 0.8 & $30,800,000$ & \\
Sub-Saharan Africa & 5.0 & $20,300,000$ & $65.9 \%$ \\
South and South-East Asia & 0.3 & $4,000,000$ & $13.0 \%$ \\
North America & 0.5 & $1,500,000$ & $4.9 \%$ \\
Eastern Europe and Central Asia & 0.8 & $1,400,000$ & $4.5 \%$ \\
Central and South America & 0.5 & $1,400,000$ & $4.5 \%$ \\
Western and Central Europe & 0.2 & 820,000 & $2.7 \%$ \\
East Asia & 0.1 & 760,000 & $2.5 \%$ \\
Middle East and North Africa & 0.2 & 440,000 & $1.4 \%$ \\
Caribbean & 1.0 & 220,000 & $0.7 \%$ \\
Oceania & 0.3 & 54,000 & $0.2 \%$ \\
\hline
\end{tabular}

Note. Data for this table are from the UNAIDS (2010) Global Report on the AIDS Epidemic: The Global Reference Book on the AIDS Epidemic and Response. Available at: http://www.unaids.org/globalreport/Global_report.htm 
Table 2

HIV prevalence and per capita alcohol consumption (in liters of pure alcohol) in sub-Saharan Africa

\begin{tabular}{|c|c|c|c|c|c|c|}
\hline \multirow[b]{2}{*}{ Country } & \multirow[t]{2}{*}{ 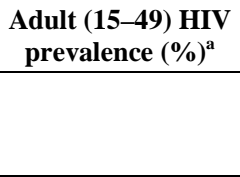 } & \multicolumn{2}{|c|}{$\begin{array}{l}\text { Adult }(15+) \text { per capita } \\
\text { alcohol consumption }\end{array}$} & \multicolumn{3}{|c|}{$\begin{array}{l}\text { Adult }(15+) \text { per capita alcohol consumption } \\
\text { among drinkers only (liters of pure alcohol) }\end{array}$} \\
\hline & & $\begin{array}{l}\text { Liters of } \\
\text { pure } \\
\text { alcohol }\end{array}$ & $\begin{array}{c}\% \\
\text { abstainers } \\
\text { (last year) }\end{array}$ & All adults & Men & Women \\
\hline \multicolumn{7}{|l|}{ Southern Africa } \\
\hline Botswana & 24.8 & 8.0 & $70.0 \%$ & 26.47 & 29.07 & 15.02 \\
\hline Lesotho & 23.6 & 5.6 & $65.8 \%$ & 16.23 & 18.66 & 10.47 \\
\hline Namibia & 13.1 & 9.6 & $69.6 \%$ & 31.64 & 35.99 & 25.17 \\
\hline South Africa & 17.8 & 9.5 & $72.9 \%$ & 34.91 & 39.64 & 23.84 \\
\hline Swaziland & 25.9 & 5.7 & $74.2 \%$ & 20.96 & 33.89 & 4.73 \\
\hline \multicolumn{7}{|l|}{ East Africa } \\
\hline Burundi & 3.3 & 9.5 & - & - & - & - \\
\hline Comoros & 0.1 & 0.4 & $99.0 \%$ & 37.02 & 45.72 & 24.25 \\
\hline Eritrea & 0.8 & 1.5 & $60.3 \%$ & 3.88 & 4.93 & 2.07 \\
\hline Ethiopia & - & 4.0 & $72.3 \%$ & 14.51 & 21.65 & 7.22 \\
\hline Kenya & 6.3 & 4.1 & $85.4 \%$ & 28.36 & 31.56 & 19.00 \\
\hline Madagascar & 0.2 & 1.3 & $70.3 \%$ & 4.48 & 4.90 & 3.22 \\
\hline Malawi & 11.0 & 1.7 & $88.8 \%$ & 15.54 & 15.35 & 12.95 \\
\hline Mauritius & 1.0 & 3.7 & $53.6 \%$ & 8.02 & 10.29 & 4.26 \\
\hline Mozambique & 11.5 & 2.4 & $56.6 \%$ & 5.48 & 6.26 & 3.79 \\
\hline Rwanda & 2.9 & 9.8 & - & - & - & - \\
\hline Seychelles & - & 10.6 & $12.8 \%$ & 12.14 & 17.34 & 8.12 \\
\hline Uganda & 6.5 & 11.9 & $56.2 \%$ & 28.16 & 37.64 & 16.59 \\
\hline Tanzania & 5.6 & 6.8 & $78.8 \%$ & 31.84 & 43.14 & 21.49 \\
\hline Zambia & 13.5 & 3.9 & $83.9 \%$ & 23.94 & 24.86 & 21.36 \\
\hline Zimbabwe & 14.3 & 5.1 & $85.6 \%$ & 35.25 & 36.69 & 25.53 \\
\hline \multicolumn{7}{|l|}{ Middle Africa } \\
\hline Angola & 2.0 & 5.4 & - & - & - & - \\
\hline Cameroon & 5.3 & 7.6 & $44.7 \%$ & 13.74 & 17.20 & 9.34 \\
\hline Central African Republic & 4.7 & 3.4 & - & - & - & - \\
\hline Chad & 3.4 & 4.4 & $78.9 \%$ & 20.68 & 26.16 & 14.23 \\
\hline Congo & 3.4 & 4.2 & $61.0 \%$ & 11.25 & 14.32 & 7.05 \\
\hline Dem. Rep. of Congo & $1.2-1.6$ & 3.3 & $56.3 \%$ & 7.55 & 9.00 & 5.19 \\
\hline Equatorial Guinea & 5.0 & 6.1 & - & - & - & - \\
\hline Gabon & 5.2 & 9.3 & - & - & - & - \\
\hline Sao Tome and Principe & - & 8.7 & $13.5 \%$ & 10.10 & 12.51 & 6.68 \\
\hline \multicolumn{7}{|l|}{ Western Africa } \\
\hline Benin & 1.2 & 2.2 & $41.5 \%$ & 3.67 & 4.18 & 2.70 \\
\hline Burkina Faso & 1.2 & 7.0 & $76.1 \%$ & 29.24 & 39.70 & 18.81 \\
\hline Cape Verde & - & 5.0 & $51.8 \%$ & 10.30 & 11.63 & 7.62 \\
\hline Cote d'Ivoire & 3.4 & 6.5 & $76.3 \%$ & 27.29 & 31.00 & 16.49 \\
\hline Gambia & 2.0 & 3.4 & - & - & - & - \\
\hline Ghana & 1.8 & 3.0 & $70.4 \%$ & 10.03 & 12.54 & 6.91 \\
\hline Guinea & 1.3 & 0.8 & - & - & - & - \\
\hline Guinea-Bissau & 2.5 & 3.7 & - & - & - & - \\
\hline Liberia & 1.5 & 5.0 & - & - & - & - \\
\hline Mali & 1.0 & 1.0 & $97.2 \%$ & 36.87 & 62.17 & 1.76 \\
\hline Mauritania & 0.7 & 0.1 & $98.8 \%$ & 9.17 & 12.88 & 2.61 \\
\hline Niger & 0.8 & 0.3 & - & - & - & - \\
\hline Nigeria & 4.6 & 12.3 & $61.7 \%$ & 32.06 & 36.86 & 22.99 \\
\hline Senegal & 0.9 & 0.6 & $98.0 \%$ & 30.00 & 33.45 & 15.27 \\
\hline Sierra Leone & 1.6 & 9.7 & $60.9 \%$ & 24.86 & 31.67 & 16.73 \\
\hline Togo & 3.2 & 2.0 & - & - & - & - \\
\hline
\end{tabular}

${ }^{a}$ HIV prevalence data for this table are from the UNAIDS (2010) Global Report on the AIDS Epidemic: The Global Reference Book on the AIDS Epidemic and Response, available at: http://www.unaids.org/globalreport/Global_report.htm

${ }^{\mathrm{b}}$ Alcohol consumption data for this table are from the WHO Global Status Report on Alcohol and Health 2011, available at: http://www.who.int/substance_abuse/publications/global_alcohol_report/en/ 
(Mitsunaga \& Larsen, 2008; Mmbaga et al., 2007; Seme, Mariam, \& Worku, 2005). These additional three studies were likely not included in our review due to the use of different electronic databases (PsycINFO vs. PubMed). Consequently, both databases were targeted in the updated search described below. In sum, a total of 30 studies from previous reviews were included in this meta-analysis.

Both the PsycINFO and PubMed databases were systematically searched for articles published from 2009 to the present using the following keywords: Africa, alcohol (or drinking or substance), and HIV (or STD or STI). Other inclusion criteria (for all the studies) were that they were published in a peer reviewed journal, included an assessment of alcohol use as an exposure (with a no-use comparison group), and included measurement of HIV status (confirmed by biologic testing) as an outcome variable. All study types were included (e.g., crosssectional, case-control, and cohort) irrespective of the measure of alcohol use employed, as long as a "no-use" referent was available for comparison. Five additional studies were identified by the updated literature review (Adoga et al., 2009; Kalichman, Cain, \& Simbayi, 2010; Norris, Kitali, \& Worby, 2009; Shaffer et al., 2010; Williams et al., 2009) bringing the total number of studies included in this meta-analysis to 35 (see Table 3).

\section{Data abstraction}

The odds ratio $(O R)$ was the chosen measure of association, as most of the studies identified presented results as unadjusted odds ratios (UORs) and/or adjusted odds ratios (AORs), or provided enough data that an $O R$ could be calculated. There were a few notable exceptions: (1) Ayisi et al. (2000) reported adjusted and unadjusted risk ratios, (2) Talbot et al. (2002) reported adjusted and unadjusted prevalence ORs, and (3) all but two of the cohort studies (Allen et al., 1992; Kalichman et al., 2010) provided rate ratios or data for calculation of a rate ratio (Kapiga et al., 1998; Shaffer et al., 2010; Zablotska et al., 2006, 2009). In these instances, the measure of association reported by the authors was used in order to retain the benefit of adjusted rate/risk ratios, although separate analyses were conducted based on study design (e.g., case-control vs. cohort studies). Several studies provided multiple measurements of alcohol use. In these cases, situational association measurements were chosen over global assessments in the meta-analysis of all studies combined, and validated measures (e.g., the Alcohol Use Disorders Identification Test [AUDIT]) were chosen over non-validated measures. Eight studies reported multiple levels of exposure to alcohol consumption (e.g., categories of number of days per week that alcohol was consumed), and in these cases, the highest level of exposure was compared to a no-use referent.

\section{Statistical procedures}

The pooled $O R$ estimate was calculated using both the fixed inverse variance weighting method (Greenland, 1998) and the random effects method when evidence of heterogeneity was present (DerSimonian \& Laird, 1986). Forest plots were used to examine individual and pooled effects. In all meta-analyses, evidence of heterogeneity across studies was evaluated using a chi-square test. For meta-analyses that provided evidence of heterogeneity $\left(\chi^{2}>\right.$ degrees of freedom), both the random effects model was performed and the fixed effects 95\% confidence interval (CI) was adjusted using the Shore method (Shore, Gardner, \& Pannett, 1993) to account for between-study variance. Publication bias was evaluated using funnel plots and the Begg and Egger tests (Begg, 1994; Egger, Smith, Schneider, \& Minder, 1997). We also conducted various subgroup meta-analyses in order to identify possible biases, sources of heterogeneity, and susceptible subgroups (Juni, Wirschi, Bloch, \& Egger, 1999). These subgroup analyses are described below.

\section{Adjustment for confounders}

The meta-analysis of all studies combined included the 20 studies that provided ORs adjusted for age, and the remaining 15 studies that provided UORs. All of the studies with AORs adjusted for age and some adjusted for various other factors, including education, religion, ethnicity, tribal affiliation, condom use, marital status, STI history, and number of sexual partners. In order to evaluate the importance of adjusting for these factors, subgroup analyses were conducted with the 20 studies that provided ORs adjusted for age, the 34 studies that provided UORs (one study only provided an AOR), and the 19 studies that provided both types of ORs (one with only UORs and one with AORs).

\section{Study design}

Because certain biases are associated with particular study designs, subgroup analyses were conducted separately for cohort, case-control and cross-sectional studies.

\section{HIV prevalence}

It is noteworthy that a majority of the studies reviewed used the $O R$ as the measure of association, even when HIV prevalence exceeded $10 \%$. Given that the OR can overestimate the risk or rate ratio when the outcome is not "rare," subgroup analyses were conducted for studies in which the HIV prevalence was greater than $10 \%$ compared to studies in which the prevalence was $10 \%$ or less (Zocchetti, Consonni, \& Bertazzi, 1997).

\section{Alcohol used in sexual contexts}

We also evaluated the hypothesis that alcohol used in sexual contexts places one at increased risk of HIV infection, by performing a subgroup meta-analysis that included only studies in which situational alcohol consumption was assessed.

\section{Assessment of alcohol use}

Several studies included in this meta-analysis used validated measures for assessing risk of developing an alcohol use disorder (AUD), while others used frequency measures of alcohol intake, or less informative binary measures of history (e.g., ever/never) of alcohol use. In an effort to assess both the quality of the alcohol exposure 


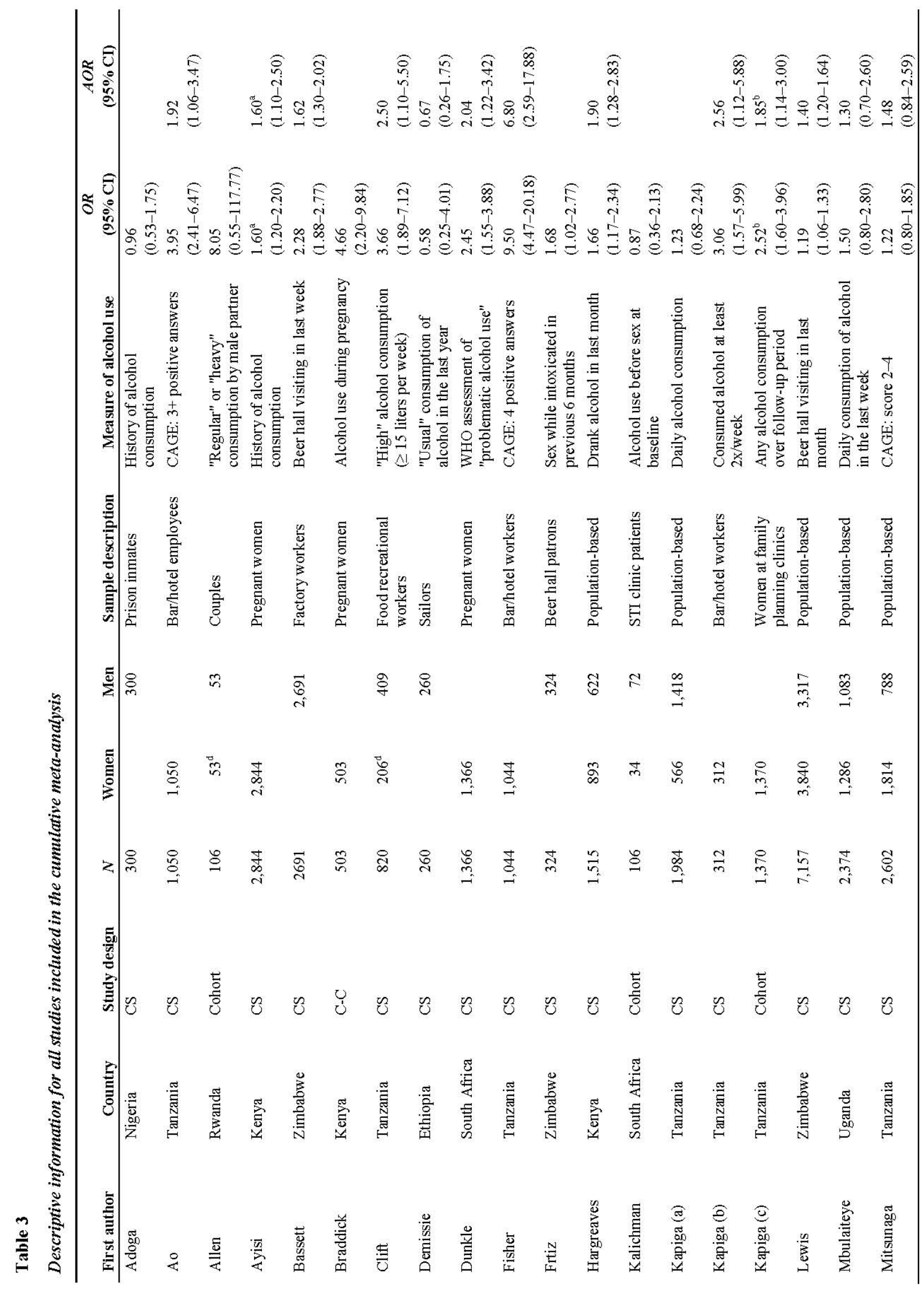




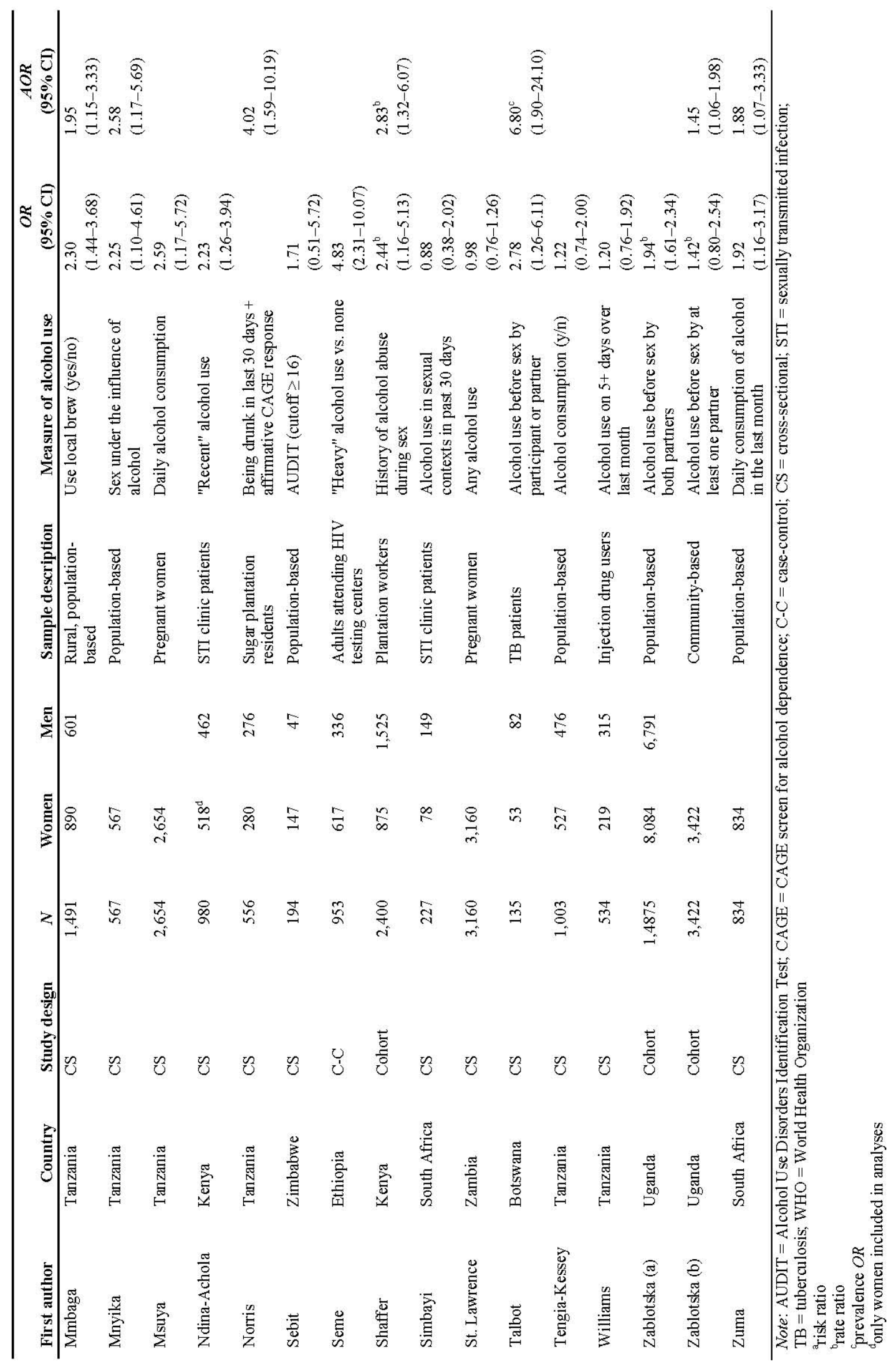


assessment and the effect of dose, subgroup analyses were conducted by the approach to alcohol exposure assessment used. Any study that used the $\mathrm{CAGE}^{1}$ clinical screen for alcohol dependence (Mayfield, McCleod, \& Hall, 1972), the AUDIT (Babor, Biddle-Higgins, Saunders, \& Monteiro, 2001), or WHO's assessment of alcohol-related problems was classified as having assessed "alcohol use that indicates risk of developing an AUD." "Frequent" use included studies where participants reported "daily" and/or "heavy" use, while "history/current" use included the aforementioned studies that reported any binary measures of current or historical use.

\section{Participant characteristics}

Similar to the observations of Fisher and colleagues, there were four distinct subgroups in the studies reviewed: men vs. women and high-risk vs. population-based. Any study that assessed an identified subpopulation (e.g., bar or hotel employees, sailors, beer hall patrons, pregnant women) was classified as "high-risk," while studies that assessed a community or population-based sample were classified as "population-based."

\section{Results}

\section{Cumulative meta-analysis}

The results of the meta-analysis of all studies combined are depicted in Figure 1. The pooled OR was 1.61 (95\% CI: 1.44-1.80). The overall chi-square test statistic showed evidence of heterogeneity $\left(\chi^{2}=82.44, p<0.01\right)$. The pooled $O R$ for the meta-analysis using only AORs was 1.64 (95\% CI: 1.45-1.85), which was only slightly different from the pooled OR using only the UORs $(1.61,95 \% \mathrm{CI}$ : $1.40-1.84)$.

\section{Sensitivity analyses}

Three studies in this meta-analysis accounted for a disproportionate amount of weight compared to the rest of the studies (Bassett et al., 1996; Lewis et al., 2005; Zablotska et al., 2006). The meta-analysis was re-run excluding these three studies and there was effectively no change in the pooled $O R$ estimate $(1.61,95 \%$ CI: 1.38 1.88). Additionally, the cumulative meta-analysis was executed in the absence of several outliers visible in Figure 1 (OR > 3.0) (Allen et al., 1992; Braddick et al., 1990; Fisher et al., 2008; Norris et al., 2009; Seme et al., 2005; Talbot et al., 2000). These studies were not allocated a significant amount of weight and the pooled $O R$ estimate again changed very little (1.54, 95\% CI: 1.40-1.70).

Figure 2 presents the funnel plot for assessment of publication bias; some evidence of asymmetry is visible.

\footnotetext{
${ }^{1}$ CAGE is an acronym for the following four questions used to assess problematic drinking: Have you ever felt you should cut down on drinking? Have people ever annoyed you by criticizing your drinking? Have you ever felt bad or guilty about your drinking? Have you ever had a drink first thing in the morning (eye-opener)?
}

The Begg test found a weak correlation between the standard error and the logarithm of the $O R(p=0.04)$ and the Egger test found a modest coefficient for bias (1.04, $p=$ 0.03 ). Based on these findings, and because publication bias tends to affect smaller studies, the studies were ranked in order of sample size and split into studies with samples of less than $1,000(n=17)$ and 1,000 or more $(n=18)$. There was a modest difference in the $O R$ estimates for the "small" studies $(O R=1.85,95 \%$ CI: $1.40-2.45)$ and "large" studies $(O R=1.56,95 \% \mathrm{CI}$ : 1.39-1.76), although this difference was not statistically significant $(p=0.27)$.

\section{Subgroup analyses}

Several differences were noted in the subgroup analyses presented in Table 2. First, $O R$ estimates differed significantly by study design such that the case-control studies produced the largest $(O R=4.75,95 \% \mathrm{CI}: 2.81-8.02)$, followed by the cohort studies $(O R=1.80,95 \% \mathrm{CI}: 1.51-$ $2.16)$ and the cross-sectional studies $(O R=1.51,95 \% \mathrm{CI}$ : 1.33-1.70), although this may be due to the fact that there were only two case-control studies. Thirteen studies included groups in which the prevalence or incidence of HIV infection was $10 \%$ or less. Three of these studies reported rate ratios, while the remaining 10 reported $O R$ estimates. In a meta-analysis of these 10 studies, the pooled OR estimate was 1.54 (95\% CI: 1.24-1.90). Of the 22 studies that included samples with an HIV prevalence of greater than $10 \%$, one (Ayisi et al., 2000) reported a risk ratio, while the others reported $O R$ estimates. In a metaanalysis of these 21 studies, the pooled $O R$ estimate was very similar to the $O R$ in the studies with HIV prevalence of $10 \%$ or less $(O R=1.53,95 \%$ CI: $1.30-1.80)$.

The odds of being HIV-positive among individuals who reported using alcohol in sexual contexts were 1.79 times (95\% CI: 1.47-2.18) those of individuals who did not report using alcohol in sexual situations. Individuals whose drinking was suggestive of an AUD had roughly twice the odds of being HIV-positive compared to non-drinkers (OR $=2.17,95 \%$ CI: 1.48-3.17), and frequent use of alcohol was also associated with significantly higher odds of being HIV-positive compared to no use $(O R=1.78,95 \% \mathrm{CI}$ : 1.29-2.48). Alcohol use suggestive of an AUD produced a significantly $(p<0.01)$ higher $O R$ estimate than the binary measure of history/recent use $(O R=1.36$; $95 \% \mathrm{CI}$ : $1.08-$ 1.71

Women who consumed alcohol appeared to have slightly higher odds of being HIV-positive $(O R=1.65,95 \% \mathrm{CI}$ : $1.42-1.92)$ than men who consumed alcohol $(O R=1.49$, 95\% CI: 1.32-1.69), although this difference was not statistically significant $(p=0.29)$. Only a slight difference in the odds of HIV-positive status was observed when separating studies that used population-based sampling (OR $=1.59,95 \%$ CI: 1.44-1.77) from studies that used targeted samples $(O R=1.76,95 \%$ CI: $1.42-2.18)$, but again, this difference was not statistically significant $(p=0.40)$. 
Figure 1

Summary of cumulative meta-analysis with unadjusted and adjusted odds ratios

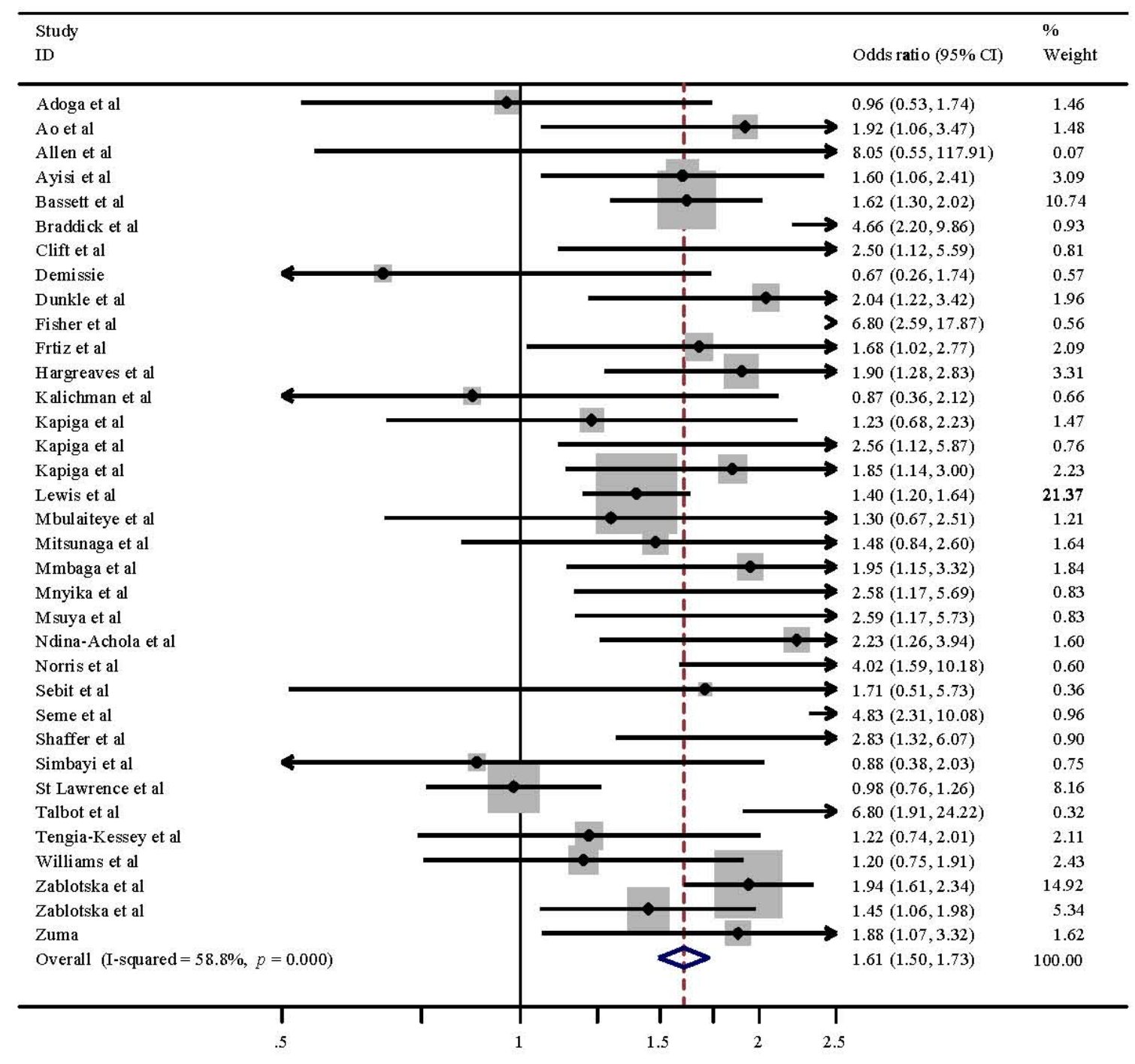

\section{Discussion}

A total of 35 studies on the relationship between alcohol use and risk of HIV infection in SSA were included in this meta-analysis. The results revealed a strong, consistent, positive relationship between self-reported alcohol use and the odds of HIV infection; this association changed very little and remained significant after adjusting for age and other factors and after removing outliers. The association was robust among both "high-risk" and population-based samples of men and women who consumed varying amounts of alcohol. However, the relationship appeared to be particularly strong among individuals who reported alcohol use indicative of risk for development of an AUD, with an odds of HIV positivity being more than twice the odds for non-drinkers. What is noteworthy in the findings is the observed increase in odds with increasing levels of alcohol consumption, supporting the presence of a doseresponse relationship between alcohol use and risk of HIV infection.

The results of this meta-analysis of 35 studies are very similar to those observed by Fisher et al. (2007) from their meta-analysis of 20 studies. Specific to this meta-analysis is the finding that consumption of alcohol in sexual contexts (compared to no use of alcohol) was associated with a nearly two-fold increase in the odds of HIV infection. This offers some evidence that the pursuit of alternative approaches to characterize alcohol use as related to HIV infection at the level of the sexual event is warranted. In fact, cross-sectional data on the global association between frequency of alcohol use and risk of HIV infection seem to have reached a point of saturation. 
Figure 2

Funnel plot with pseudo 95\% confidence limits for assessment of bias

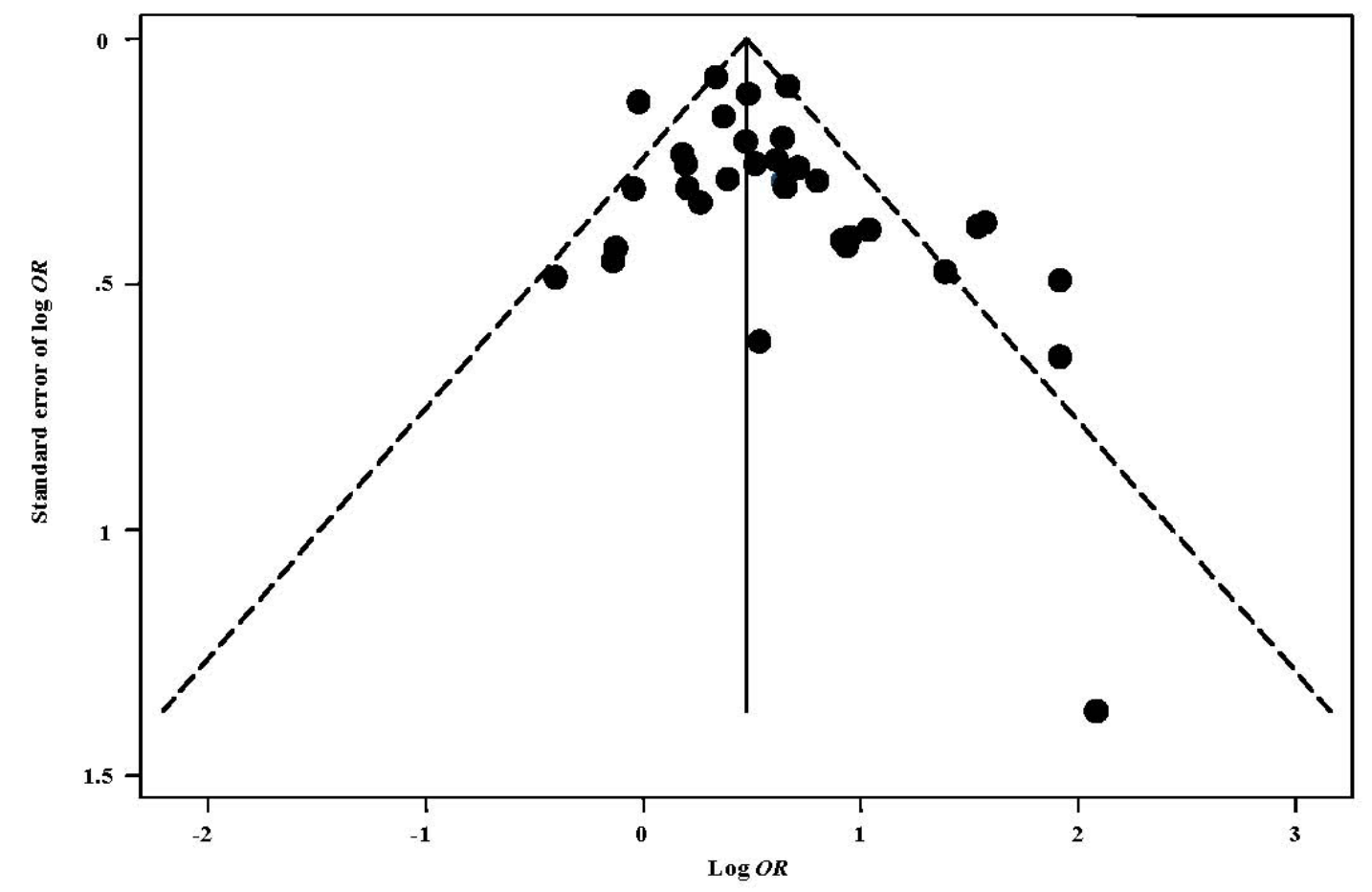

Note. Egger: Bias $=1.05$ (95\% CI: .13 to 1.98), $p=0.03$; Begg: Kendall's Tau $=143, p=0.04$.

An increased focus on methods that allow for more sensitive tests of the event-level association between alcohol consumption and HIV infection may better serve the field.

\section{Limitations}

The funnel plot depicted in Figure 2 revealed some possible asymmetry, which was somewhat corroborated by significant results from both the Begg and Egger tests (Begg, 1994; Egger et al., 1997). Publication bias refers to the possibility that "negative" findings may be underrepresented in the published literature. Because small studies are more likely to be affected (Greenland, 1998), a subgroup analysis was conducted by study sample size. The $O R$ was slightly higher in the smaller studies, but the difference was not statistically significant. Thus, while there is some evidence of publication bias, these findings suggest that it does not explain the overall observed effect.

We considered age as a confounder of interest given that age is associated with both alcohol consumption (WHO, 2011) and HIV infection (UNAIDS, 2006) in SSA. There were virtually no observed differences in the pooled UOR and the pooled $A O R$ estimates across studies, even when comparing studies that provided both measures of association. However, the variables that were included in the multivariate models may not have captured all relevant confounders of the association between alcohol intake and HIV infection. More thoughtful measurement of additional confounders (e.g., personality type) may allow for a better understanding of the relationship between alcohol use and HIV status (Kalichman, Simbayi, Jooste, Cain, \& Cherry, 2006).

Variability in the approach to assessing alcohol use is a significant problem. The subgroup analysis that included well-validated assessments of problematic alcohol use (e.g., AUDIT) provided some evidence that more homogeneous exposure assessments were still strongly associated with an increase in the odds of HIV infection. Nevertheless, the field would benefit from a move towards more accurate, precise, and uniform exposure assessment.

\section{Conclusions}

The studies reviewed here were largely cross-sectional and included a measure of alcohol use as one of a multitude of variables under investigation. While this approach can be helpful in the identification of risk factors, once the risk factor has been observed repeatedly, a more refined understanding of the way in which the exposure is related to the outcome is necessary. Given the situational association studies reviewed here, an increased focus on event-level alcohol use and associated high-risk sexual behavior would assist in both the identification of the causal mechanisms underlying the ubiquitous correlation between alcohol and HIV and subsequently add to the still nascent literature on intervention development. 


\section{References}

Adoga, M. P., Banwat, E. B., Forbi, J. C., Nimzig, L., Pam, C. R., Gyar, S.D., . . . Agwale, S. M. (2009). Human immunodeficiency virus, hepatitis $\mathrm{B}$ virus, and hepatitis C virus: Sero-prevalence, co-infection and risk factors among prison inmates in Nasarawa State, Nigeria. Journal of Infection in Developing Countries, 3, 539-547.

Allen, S., Tice, J., Van de Perre, P., Serufilira, A., Hudes, E., Nsengumuremyi, F., ... Hulley, S. (1992). Effect of serotesting with counseling on condom use and seroconversion among HIV discordant couples in Africa. British Medical Journal, 304, 1605-1609.

Ao, T. T. H, Sam, N. E., Masenga, E. J., Seage G. R., III, \& Kapiga, S. H. (2006). Human immunodeficiency virus type 1 among bar and hotel workers in northern Tanzania: The role of alcohol, sexual behavior, and herpes simplex virus type 2. Sexually Transmitted Diseases, 33, 163-169.

Ayisi, J. G., Van Eijk, A. M., Kuile, F. O. T., Kolczak, M. S., Otieno, J. A., \& Misore, A. O. (2000). Risk factors for HIV infection among asymptomatic pregnant women attending an antenatal clinic in western Kenya. International Journal of STD \& AIDS, 11, 393-401.

Babor, T. F., Biddle-Higgins, J. C., Saunders, J. B. \& Monteiro, M. G. (2001). AUDIT: The Alcohol Use Disorders Identification Test. Guidelines for use in primary health care. Geneva, Switzerland: World Health Organization.

Bassett, M. T., McFarland, W. C., Ray, S., Mbizvo, M. T., Machekano, R., van de Wijgert, J. H. H. M., \& Katzenstein, D. A. (1996). Risk factors for HIV infection at enrollment in an urban male factory cohort in Harare, Zimbabwe. Journal of Acquired Immune Deficiency Syndromes, 13, 287-293.

Begg, C. B. (1994). Publication bias. In H. Cooper \& L. V. Hedges (Eds.), Handbook of research synthesis (pp. 399-409). New York, NY, United States: Russell Sage Foundation.

Braddick, M. R., Kreiss, J. K., Embree, J. E., Datta, P., Ndinya-Achola, J. O., Pamba H., ... Holmes, K. K. (1990). Impact of maternal HIV infection on obstetrical and early neonatal outcome. AIDS, 4, 1001-1006.

Clift, S., Anemona, A., Watson-Jones, D., Kanga, Z., Ndeki, L., Changalucha, J., ... Ross, D. A. (2003). Variations of HIV and STI prevalence within communities neighbouring new goldmines in Tanzania: Importance for intervention design. Sexually Transmitted Infection, 79, 307-312.

Cooper, M. L. (2002). Alcohol use and risky sexual behavior among college students and youth: Evaluating the evidence. Journal of Studies on Alcohol, Suppl 14, 101-117.

Demissie, K., Amre, D., \& Tsega, E. (1996). HIV-1 infection in relation to educational status, use of hypodermic injections and other risk behaviors in Ethiopian sailors. East African Medical Journal, 73, 819-822.

DerSimonian, R., \& Laird, N. (1986). Meta-analysis in clinical trials. Controlled Clinical Trials, 7, 177-188.
Dingle, G. A., \& Oei, T. P. (1997). Is alcohol a cofactor of HIV and AIDS? Evidence from immunological and behavioral studies. Psychological Bulletin, 122, 5671.

Dunkle, K. L., Jewkes, R. K., Brown, H. C., Gray, G. E., McIntryre, J. A., \& Harlow, S. D. (2004). Genderbased violence, relationship power, and risk of HIV infection in women attending antenatal clinics in South Africa. Lancet, 363, 1415-1421.

Egger, M., Smith, G. D., Schneider, M., \& Minder, C. (1997). Bias in meta-analysis detected by a simple graphical test. British Medical Journal, 315, 629-634.

Fisher, J. C., Bang, H., \& Kapiga, S. H. (2007). The association between HIV infection and alcohol use: A systematic review and meta-analysis of African studies. Sexually Transmitted Diseases, 34, 856-863.

Fisher, J. C, Cook, P. A., Sam, N. E., \& Kapiga, S. H. (2008). Patterns of alcohol use, problem drinking, and HIV infection among high-risk African women. Sexually Transmitted Diseases, 35, 537-544.

Fritz, K. E., Woelk, G. B., Bassett, M. T., McFarland, W. C., Routh, J. A., Tobaiwa, O., ... Stall, R. D. (2002). The association between alcohol use, sexual risk behavior, and HIV infection among men attending beer halls in Harare, Zimbabwe. AIDS and Behavior, 6, 221-228.

Gilgen, D., Williams, B. G., \& Campbell, C. M. (2000). HIV/AIDS in Careltonville: The 1998 survey, Johannesburg. Pretoria, South Africa: Council for Scientific and Industrial Research.

Goldman, M. S., Del Boca, F. K., \& Darkes, J. (1999). Alcohol expectancy theory: The application of cognitive neuroscience. In K. E. Leonard \& H. T. Blane (Eds.), Psychological theories of drinking and alcoholism, (2nd ed., pp. 203-326). New York, NY, United States: Guilford Press.

Greenland, S. (1998). Meta-analysis. In K. J. Rothman, \& S. Greenland (Eds.), Modern epidemiology (pp. 643673). Philadelphia, PA, United States: LippincottRaven.

Hargreaves, J. R., Morison, L. A., Chege, J., Rutenburg, N., Kahindo, M., Weiss, H. A., ... Buvé, A. (2002). Socioeconomic status and risk of HIV infection in an urban population in Kenya. Tropical Medicine and International Health, 7, 793-780.

Hendershot, C., \& George, W. H. (2007). Alcohol and sexuality research in the AIDS era: Trends in publication activity, target populations, and research designs. AIDS and Behavior, 11, 217-226.

Juni, P., Wirschi, A., Bloch, R., \& Egger, M. (1999). The hazards of scoring the quality of clinical trial for metaanalysis. Journal of the American Medical Association, 282, 1054-1060.

Kalichman, S. C., Cain, D., \& Simbayi, L. C. (2010). Behavioral changes associated with testing HIVpositive among sexually transmitted infection clinic patients in Cape Town, South Africa. American Journal of Public Health, 100, 714-719.

Kalichman, S. C., Simbayi, L. C., Kaufman, M., Cain, D., \& Jooste, S. (2007). Alcohol use and sexual risks for HIV/AIDS in sub-Saharan Africa: Systematic review of empirical findings. Prevention Science, 8, 141-151. 
Kalichman, S. C., Simbayi, L. C., Jooste, S., Cain, D., \& Cherry, C. (2006). Sensation seeking, alcohol use and sexual behaviors among sexually transmitted infection clinic patients in Cape Town, South Africa. Psychology of Addictive Behavhaviors, 20, 298-304.

Kapiga, S. H., Sam, N. E., Mlay, J., Aboud, S., Ballard, R. C., Shao, J. F., \& Larsen, U. (2006). The epidemiology of HIV-1 infection in northern Tanzania: Results from a community-based study. AIDS Care, 18, 379-387.

Kapiga, S. H., Sam, N. E., Shao, J. F., Renjifo, B., Masenga, E. J., Kiwelu, I. E., ... Essex, M. (2002). HIV-1 epidemic among female bar and hotel workers in northern Tanzania: Risk factors and opportunities for prevention. Journal of Acquired Immune Deficiency Syndromes, 29, 409-417.

Kapiga, S. H., Lyamuya, E. F., Lwihula, G. K., \& Hunter, D. J. (1998). The incidence of HIV infection among women using family planning methods in Dar es Salaam, Tanzania. AIDS, 12, 75-84.

Lewis, J. C., Garnett, G. P., Mhlanga, S., Nyamukapa, C. A., Donnelly, C. A., \& Gregson, S. (2005). Beer halls as a focus for HIV prevention activities in rural Zimbabwe. Sexually Transmitted Diseases, 32, 364369.

Mayfield, D., McCleod, G., \& Hall, P. (1972). The CAGE questionnaire: Validation of a new alcoholism screening instrument. American Journal of Psychiatry, 131, 1121-1123.

Mbulaiteye, S. M., Ruberantwari, A., Nakiyingi, J. S., Carpenter, L. M., Kamal, A., \& Whitworth, J. A. G. (2000). Alcohol and HIV: A study among sexually active adults in rural southwest Uganda. International Journal of Epidemiology, 29, 911-915.

Mitsunaga, T., \& Larsen, U. (2008). Prevalence of and risk factors associated with alcohol abuse in Moshi, Northern Tanzania. Journal of Biological Sciences, 40, 379-399.

Mmbaga, E. J., Hussain, A., Leyna, G. H., Mnyika, K. S., Sam, N. I., \& Klepp, K.-I. (2007). Prevalence and risk infection in rural Kilimanjaro region of Tanzania: Factors for HIV-1, implications for prevention and treatment. BMC Pubic Health, 7, 58.

Mnyika, K. S., Klepp, K.I., Kvåle, G., \& Ole-King'ori, N. (1996). Risk factors for HIV-1 infection among women in the Arusha region of Tanzania. Journal of Acquired Immune Deficiency Syndromes and Human Retrovirology, 11, 484-491.

Msuya, S. E., Mbizvo, E., Hussain, A., Uriyo, J., Sam, N. E., \& Stray-Pedersen, B. (2006). HIV among pregnant women in Moshi Tanzania: The role of sexual behavior, male partner characteristics and sexually transmitted infections. AIDS Research and Therapy, 3, 27-10.

Ndina-Achola, J. O., Ghee, A. E., Kihara, A. N., Krone, M. R., Plummer, F. A., Fisher, L. D., \& Holmes, K. K. (1997). High HIV prevalence, low condom use and gender differences in sexual behavior among patients with STD-related complaints at a Nairobi primary health care clinic. International Journal of STD \& AIDS, 8, 506-514.
Norris, A. H., Kitali, A. J., \& Worby, E. (2009). Alcohol and transactional sex: How risky is the mix? Social Science \& Medicine, 69, 1167-1176.

Pithy, A., \& Parry, C. (2009). Descriptive systematic review of sub-Saharan African studies on the association between alcohol use and HIV infection. Journal of Social Aspects of HIV/AIDS, 6, 155-169.

Sebit, M. B., Tombe, M., Siziya, S., Balus, S., Nkomo, S. D. A., \& Maramba, P. (2003). Prevalence of HIV/ AIDS and psychiatric disorders and their related risk factors among adults in Epworth, Zimbabwe. East African Medical Journal, 80, 503-512.

Seme, A., Mariam, D. H., \& Worku, A. (2005). The association between substance abuse and HIV infection among people visiting HIV counseling and testing centers in Addis Ababa, Ethiopia. Ethiopian Journal of Health Development, 19, 116-125.

Shaffer, D. N., Ngetich, I. K., Bautista, C. T., Sawe, F. K., Renzullo, P. O., \& Scott, P. T. (2010). HIV-1 incidence rates and risk factors in agricultural workers and dependents in rural Kenya: 36-month follow-up of the Kericho HIV cohort study. Journal of Acquired Immune Deficiency Syndromes, 53, 514-521.

Shore, R. E., Gardner, M. J., \& Pannett, B. (1993). Ethylene oxide: An assessment of the epidemiological evidence on carcinogenicity. British Journal of Industrial Medicine, 50, 971-997.

Simbayi, L. C., Kalichman, S. C., Jooste, S., Mathiti, V., Cain, D., \& Charsey, C. (2004). Alcohol use and sexual risks for HIV infection among men and women receiving sexually transmitted infection clinic services in Cape Town, South Africa. Journal of Studies on Alcohol, 65, 434-442.

Steele, C. M., \& Josephs, R. A. (1990). Alcohol myopia: Its prized and dangerous effects. American Psychologist, 45, 921-933.

St. Lawrence, J. S., Klaskala, W., Kankasa, C., West, J. T., Mitchell, C. D., \& Wood, C. (2006). Factors associated with HIV prevalence in a pre-partum cohort of Zambian women. International Journal of STD \& AIDS, 17, 607-613.

Talbot, E. A., Kenyon, T. A., Moeti, T. L., Hsin, G., Dooley, L., El-Halabi, S., \& Binkin, N. J. (2002). HIV risk factors among patients with tuberculosisBotswana 1999. International Journal of STD \& AIDS, 13, 311-317.

Tengia-Kessey, A., Msamanga, G. I., \& Moshino, C. S. (1998). Assessment of behavioral risk factors associated with HIV infection among youth in Moshi rural district, Tanzania. East African Medical Journal, 75, 528-532.

UNAIDS. (2006). Report on the global AIDS epidemic. Geneva, Switzerland: Author. Retrieved from www. unaids.org/en/HIV_data/2006GlobalReport/defailt.asp

Weinhardt, L. S., \& Carey, M. P. (2000). Does alcohol lead to sexual risk behavior? Findings from event-level research. Annual Review of Sex Research, 11, 125157.

Williams, M. L., McCurdy, S. A., Bowen, A. M., Kilonzo, G. P., Atkinson, J. S., Ross, M. W., \& Leshabari, M. T. (2009). HIV seroprevalence in a sample of 
Tanzanian intravenous drug users. AIDS Education and Prevention, 21, 471-483.

Woolf-King, S. E., \& Maisto, S. A. (2011). Alcohol use and high risk sexual behavior in sub-Saharan Africa: A narrative review. Archives of Sexual Behavior, 40, 17-42.

World Health Organization. (2011). Global status report on alcohol and health: 2011. Geneva, Switzerland: Author. Retrieved from http://www.who.int/sub stance_abuse/publications/global_alcohol_report/en/in dex.html

Zablotska, I. B., Gray, R. H., Koenig, M. A., Serwadda, D., Nalugoda, F., Kigozi, G., ... Wawer, M. (2009). Alcohol use, intimate partner violence, sexual coercion and HIV among women aged 15-24 in Rakai, Uganda. AIDS and Behavior, 13, 225-233.
Zablotska, I. B., Gray, R. H., Serwadda, D., Nalugoda, F., Kigozi, G., Sewankambo, N., ... Wawer, M. (2006). Alcohol use before sex and HIV acquisition: A longitudinal study in Rakai, Uganda. AIDS, 20, 11911196.

Zocchetti, C., Consonni, D., \& Bertazzi, P. A. (1997). Relationship between prevalence rate ratios and odds ratios in cross-sectional studies. International Journal of Epidemiology, 26, 220-223.

Zuma, K., Gouws, E., Williams, B., \& Lurie, M. (2003). Risk factors for HIV infection among women in Carletonville, South Africa: Migration, demography and sexually transmitted diseases. International Journal of STD \& AIDS, 14, 814-817. 